\title{
Glyceride Hydrolysis and Glycerol Fermentation by Sheep Rumen Contents
}

\author{
By G. A. GARTON, A. K. LOUGH and E. VIOQUE \\ Rowett Research Institute, Bucksburn, Aberdeen
}

(Received 28 October 1960)

\begin{abstract}
SUMMARY
Microbial hydrolysis of triglycerides was observed when these were incubated anaerobically at $37^{\circ}$ with sheep rumen contents. The extent of hydrolysis was variable, but was often considerable ( $>90 \%$ ) when linseed oil was used as substrate. The free fatty acids liberated were analysed by gas chromatography and, as compared with the acids present initially in glyceride combination, they were less unsaturated because of microbial hydrogenation. Linolenic acid was particularly effectively hydrogenated. No synthesis of long-chain fatty acids took place during the incubations and, apart from the possibility that in some experiments a limited conversion of stearic acid to palmitic acid took place, there was no evidence of significant degradation of long-chain acids. Glycerol liberated during the hydrolysis was completely metabolized, in part to volatile fatty acids, largely propionic acid. No mono- or diglycerides were detected as intermediates in the lipolysis of triglycerides. Analysis of the contents of the rumen, abomasum and small intestine of each of two slaughtered sheep, one of which had previously been fed on a diet rich in linseed oil, showed that most of the total higher fatty acids present in each of these three portions of the alimentary tract was in the form of free acids. It is concluded that microbial lipolysis results in the pre-digestion of much of the lipids ingested by the sheep as part of its feed.
\end{abstract}

\section{INTRODUCTION}

Attention was first directed to the influence of the rumen on lipids by Reiser (1951) who found a marked decrease in the linolenic acid content of linseed oil when it was incubated with sheep rumen contents. This effect was attributed to hydrogenation of double bonds by rumen micro-organisms and was substantiated by comparisons of the unsaturation of feed lipids with that of the lipids of rumen contents in sheep (Shorland, Weenink \& Johns, 1955) and goats (Reiser \& Reddy, 1956) and the detailed examination of the products of incubation of oleic, linoleic and linolenic acids with sheep rumen contents (Shorland, Weenink, Johns \& McDonald, 1957). In all the foregoing studies the total lipid of rumen contents was saponified before determination of the unsaturation of the component fatty acids. In the present work, to examine more fully the effect of mixed rumen microorganisms on esterified unsaturated fatty acids, several triglycerides were incubated with sheep rumen contents, and subsequently the lipids were extracted without previous saponification. These experiments, which resulted in the finding that 
lipolysis could be effected by rumen organisms, are reported in the present paper, together with related observations on the nature of the lipids in different parts of the alimentary tract of the sheep. Preliminary accounts of some of these results have already been published (Garton, Hobson \& Lough, 1958; Garton, Lough \& Vioque, 1959; review by Garton, 1959).

\section{METHODS}

\section{In vitro experiments}

Incubation of glycerides with rumen contents. Samples of rumen contents were obtained from sheep with permanent rumen fistulas. The animals were fed on a mixture of hay and concentrates with free access to water and the samples (100$500 \mathrm{ml}$. as required) were taken 3-4 hr. after the last feed. After thorough mixing, portions (usually $100 \mathrm{ml}$.) were transferred to sterile $250 \mathrm{ml}$. conical flasks fitted with Bunsen valves. Each flask was placed up to its neck in a water bath maintained at $37^{\circ}$, and gassed with $\mathrm{CO}_{2}$ to remove air. The $\mathrm{pH}$ value of the rumen contents was then determined by capillator (British Drug Houses, Ltd., Poole, Dorset) and adjusted when necessary to $\mathrm{pH} 6.5$ by the dropwise addition of a sterile solution of $\mathrm{Na}_{2} \mathrm{CO}_{3}(25 \%, \mathrm{w} / \mathrm{v})$. A weighed amount of glyceride, contained in a small glass cup, was then put into the rumen contents and the flask shaken; it was then flushed again with $\mathrm{CO}_{2}$. At hourly intervals thereafter for $8 \mathrm{hr}$. the flask was shaken and adjusted to $\mathrm{pH} 6 \cdot 5$. The incubation was continued overnight for a further $16 \mathrm{hr}$. after which the $\mathrm{pH}$ value was recorded and the mixture acidified to $\mathrm{pH} 2 \cdot 0$ with $10 \mathrm{~N}-\mathrm{H}_{2} \mathrm{SO}_{4}$. Other flasks containing rumen contents only, or rumen contents which had previously been heated at $90^{\circ}$ for $1 \mathrm{hr}$., were incubated at the same time and treated in the same way.

Extraction and fractionation of lipids. At the end of the incubation period $100 \mathrm{ml}$. ethanol were added to the acidified rumen contents and the mixture boiled under reflux for $10 \mathrm{~min}$. After cooling, the aqueous ethanol was decanted and $200 \mathrm{ml}$. of a mixture of ethanol and ether $(3+1, v / v)$ were added to the solid residue in the flask, which was then heated under reflux for $15 \mathrm{~min}$. The ethanol + ether extract was filtered off and the solids remaining on the filter washed with warm ethanol+ ether. The total ethanol + ether extracts were pooled with the aqueous ethanolic extract and this solution, containing the total lipid, was concentrated to $20-30 \mathrm{ml}$. by distillation on a water bath. To remove volatile fatty acids from the concentrated extract $50 \mathrm{ml}$. of a phosphate buffer ( $\mathrm{pH} 6$; containing $5.68 \mathrm{~g}$. anhydrous $\mathrm{Na}_{2} \mathrm{HPO}_{4}+49 \cdot 0 \mathrm{~g}$. anhydrous $\mathrm{KH}_{2} \mathrm{PO}_{4} /$. water) were added and the mixture was extracted thrice with $\mathbf{5 0} \mathrm{ml}$. ether, the volatile acids remaining in the buffer solution as salts.

The combined ethereal extracts were shaken gently with $3 \times 50 \mathrm{ml} .0 .5 \%(\mathrm{w} / \mathrm{v})$ aqueous $\mathrm{KOH}$, followed by one washing of the ether with $50 \mathrm{ml}$. water; this treatment removed the free higher fatty acids as potassium soaps, leaving neutral lipids in solution in the ether. The solution of soaps was acidified dropwise with $10 \mathrm{~N}-$ $\mathrm{H}_{2} \mathrm{SO}_{4}$ until no further precipitation of fatty acids took place. The acids were extracted thrice with $50 \mathrm{ml}$. ether and the combined ethereal extracts washed with water until free from mineral acid. The extract was then taken to dryness in vacuo in a tared flask to give the weight of free higher fatty acids, which were stored 
under $\mathrm{N}_{2}$ at $+1^{\circ}$ in the dark. After allowing for the weight of free fatty acids in the rumen contents alone, the extent of hydrolysis of a glyceride was derived from the weight of free fatty acids liberated expressed as \% of the calculated weight of acids produced on complete hydrolysis of the glyceride. The slight increase in weight of the free acids resulting from the hydrogenation of unsaturated components was neglected.

In some experiments the alkali-extracted ethereal solution of neutral lipids was fractionated further; the solution was taken to dryness and saponified under reflux with excess $0.5 \mathrm{~N}$-ethanolic $\mathrm{KOH}$. The saponified mixture was acidified dropwise with $10 \mathrm{~N}-\mathrm{H}_{2} \mathrm{SO}_{4}$ and the resultant mixture of fatty acids and unsaponifiable matter extracted with $3 \times 50 \mathrm{ml}$. ether. From these combined extracts the fatty acids were recovered as described above for free fatty acids, leaving the unsaponifiable matter in the ether.

Incubation of glycerol with rumen contents. Following preliminary experiments in which glycerol was determined in rumen contents before and after the incubation with linseed oil, known amounts of free glycerol were incubated with rumen contents under the same conditions as those described for the incubation of glycerides. Glycerol was estimated by the method of Lambert \& Neish (1950) following treatment of the rumen contents according to Johns (1953).

Fatty acid analyses. The free fatty acids resulting from lipolysis and, where appropriate, those derived from the residual neutral lipids, were converted to their corresponding methyl esters by refluxing with excess methanol containing $1 \%$ (w/w) $\mathrm{H}_{2} \mathrm{SO}_{4}$. The recovered esters were analysed by gas chromatography at $170^{\circ}$ using polymerised ethylene glycol adipate (prepared according to Farquhar et al. 1959) as liquid phase and argon as carrier gas. Appropriate model mixtures of fatty acid esters were chromatographed and the fatty acid composition of the samples from the incubations was calculated as described by Farquhar et al. (1959). The fatty acid composition of the glycerides used for incubation was determined in a similar way following saponification of the material with alkali and conversion of the acids to methyl esters.

Volatile fatty acids present in rumen contents before and after incubation with a triglyceride or glycerol were determined titrimetrically following acidification and steam-distillation of rumen contents (Friedemann, 1938); the mixtures of sodium salts of fatty acids so obtained were analysed qualitatively by paper chromatography (Elsden \& Lewis, 1953).

\section{Alimentary tract contents of slaughtered sheep}

Samples of the contents of various parts of the alimentary tracts of two sheep were obtained immediately at slaughter which, for each animal, was $7 \mathrm{hr}$. after the last feed. One sheep had been fed for several months on a diet consisting largely of hay, linseed meal and maize to which $40 \mathrm{~g}$. of linseed oil were added daily; the other had been fed on a mixture of concentrates including maize meal, groundnut meal, molassine meal, dried grass, oat dust and bruised oats. Each sample of alimentary tract contents was mixed with twice its weight of absolute methanol and filtered. The residue was retained and the filtrate was distilled to dryness on a water bath; the retained solids and the methanol-extracted matter were combined and extracted under reflux with excess chloroform + methanol mixture $(2+1, v / v)$ for $15 \mathrm{~min}$. The 
mixture was filtered and the solids on the filter washed with hot chloroform + methanol, after which the combined filtrates were distilled to dryness to give the crude lipid extract. This material was dissolved in a convenient volume of ether before proceeding with fractionation into free fatty acids and neutral lipids as described above for incubated rumen contents.

\section{RESULTS}

\section{Incubation of glycerides with rumen contents}

In the first series of experiments $1 \cdot 00 \mathrm{~g}$. amounts of linseed oil were incubated with $100 \mathrm{ml}$. portions of whole rumen contents (in which the oil readily emulsified); after $24 \mathrm{hr}$. the free higher fatty acids were extracted and their iodine values determined. Hydrolysis usually resulted in the liberation of $60 \%$ to more than $90 \%$ of the esterified fatty acid residues of the original oil; occasionally the extent of hydrolysis was lower, in some experiments as low as $20 \%$. The results of two experiments showing considerable hydrolysis are given in Table 1. No lipolysis was observed in the flasks containing the rumen contents which had previously been heated (flasks 4 and 8 ) and the slight difference between the amounts of free acids recovered from flasks 3 and 4 and those from flasks 7 and 8 was due to traces of free acid present initially in the linseed oil. That hydrogenation of unsaturated acids had also taken place was indicated by the low iodine value of the recovered acids compared with the value (189.0) of the acids of the linseed oil itself; calculation gives the iodine value of the free acids derived from the oil as 121.4 (flask 2) and 112.2 (flask 6). Only traces of free glycerol were found in the rumen contents before incubation; following incubation in the presence or absence of linseed oil, none at all was detected.

Table 1. Lipolytic activity of sheep rumen contents towards linseed oil

Each flask contained $100 \mathrm{ml}$. rumen contents and, where indicated, $1.00 \mathrm{~g}$. of linseed oil.

\begin{tabular}{|c|c|c|c|c|}
\hline \multirow[b]{2}{*}{ Flask } & \multirow[b]{2}{*}{$\begin{array}{l}\text { Treatment before } \\
\text { incubation }\end{array}$} & \multirow[b]{2}{*}{ Addition } & \multicolumn{2}{|c|}{ Free fatty acids } \\
\hline & & & $\begin{array}{l}\text { Weight } \\
\text { (mg.) }\end{array}$ & $\begin{array}{l}\text { Iodine } \\
\text { value }\end{array}$ \\
\hline \multicolumn{5}{|c|}{ Experiment 1} \\
\hline 1 & None & None & 245 & $22 \cdot 8$ \\
\hline 2 & None & Linseed oil & $859^{*}$ & $97 \cdot 4$ \\
\hline 3 & $\begin{array}{l}\text { Heated at } 90^{\circ} \\
\text { for } 1 \mathrm{hr} .\end{array}$ & None & 236 & $31 \cdot 6$ \\
\hline 4 & $\begin{array}{l}\text { Heated at } 90^{\circ} \\
\text { for } 1 \mathrm{hr} \text {. }\end{array}$ & $\begin{array}{l}\text { Linseed oil } \\
\text { periment } 2\end{array}$ & 268 & $44 \cdot 7$ \\
\hline 5 & None & None & 291 & $29 \cdot 2$ \\
\hline 6 & None & Linseed oil & $1144 \dagger$ & $94 \cdot 3$ \\
\hline 7 & $\begin{array}{l}\text { Heated at } 90^{\circ} \\
\text { for } 1 \mathrm{hr} \text {. }\end{array}$ & None & 253 & $41 \cdot 3$ \\
\hline 8 & $\begin{array}{l}\text { Heated at } 90^{\circ} \\
\text { for } 1 \mathrm{hr} .\end{array}$ & Linseed oil & 311 & $50 \cdot 0$ \\
\hline
\end{tabular}

* Representing about $62 \%$ hydrolysis of the esterified fatty acids of the oil.

$\dagger$ Representing about $87 \%$ hydrolysis of the esterified fatty acids of the oil.

In other experiments similar to those outlined in Table 1 linseed oil was incubated: (i) with rumen contents from which almost all the micro-organisms had been 
removed by centrifugation; (ii) with mixed sheep saliva (kindly collected for us by our colleague Dr R. N. B. Kay). In neither case was any hydrolysis of the oil observed. It was therefore concluded that lipolysis was probably due to the bacteria and/or protozoa of the rumen contents. When differential centrifugation was used to separate food particles and large protozoa from bacteria and small protozoa, almost all the lipolytic activity was found to be associated with the latter group of mixed organisms, which consisted mainly of bacteria. Attempts were made to prepare from mixed rumen organisms a cell-free extract which possessed lipase activity, but none was successful. The methods used included acetone-powders, grinding, shaking with ballotini beads, and rupture of the organisms with various detergents.

Further incubation experiments were carried out in which the free fatty acids resulting from the hydrolysis of linseed oil, olive oil and cocoa butter by whole rumen contents were analysed by gas chromatography. In addition, neutral lipids were extracted at the conclusion of the incubation period and volatile fatty acids were determined in the rumen contents incubated with and without the addition of triglyceride. Cocoa butter and olive oil did not form such stable emulsions in rumen contents as did linseed oil, and a few small globules of these triglycerides remained on the surface of the rumen contents throughout the incubation period.

The extent to which the esterified fatty acid residues in the glycerides were hydrolysed was about $95 \%, 68 \%$ and $40 \%$, respectively, for linseed oil, olive oil and cocoa butter. The combined weight of free fatty acids and neutral lipid recovered after the incubations showed almost quantitative recovery of the total weight of triglyceride added initially, due allowance being made for the amounts of lipid in the rumen contents per se and for the small amounts of glycerol liberated in the hydrolysis. The incubation of the glycerides resulted in a slightly enhanced formation of steam-volatile fatty acids as compared with the amounts found in rumen contents incubated under the same conditions without the addition of glycerides. This was probably due to some fermentation of liberated glycerol (see later). In Table 2 are shown the amounts and composition of the free fatty acids which resulted from hydrolysis of the glycerides, the fatty acid composition of the glycerides used, and the amounts and composition of the free acids present in the rumen contents alone. It is assumed that the free fatty acids extracted from the rumen contents alone were also present in the acids extracted from the glyceride incubations; Table 1 indicates that this is a reasonable assumption since a comparison of the amounts of free fatty acids in heated and unheated rumen contents (flasks 1 and 3 and flasks 5 and 7) showed that only very small amounts of free acids were produced during the incubation from lipids initially present in the rumen contents. Further, an even smaller amount might be expected to arise in this way when triglyceride was also present because of competition for enzyme by the additional substrate. Table 2 shows that, as compared with the composition of the fatty acids present initially in the triglycerides, the acids resulting from hydrolysis were extensively modified. Hydrogenation of the $\mathrm{C}_{18}$ unsaturated fatty acids led to the production of enhanced proportions of stearic acid (cf. Shorland et al. 1957) and, in addition, palmitic acid appeared in increased proportions, particularly from linseed oil and olive oil. Small amounts of (as yet) unidentified acids were formed from linseed oil and olive oil, but not from cocoa butter. These acids, present in the 
free fatty acids of rumen contents per se, were not found in the dietary lipids of the sheep. On the gas chromatograms their methyl esters appeared in positions between methyl laurate and methyl tridecanoate, and between the latter and methyl myristate.

Whilst the studies of Shorland et al. (1957) showed that unsaturated fatty acids as such were hydrogenated when they were incubated with rumen contents, the experiments so far described here do not preclude the possibility that hydrogenation might take place whilst the acids were still in glyceride combination. Though in most of the experiments with linseed oil hydrolysis was almost complete, in others (as previously mentioned) the extent of hydrolysis was much less. Analysis of the neutral lipids remaining after partial $(20 \%$ ) hydrolysis of $1.0 \mathrm{~g}$. of linseed oil by $100 \mathrm{ml}$. rumen contents from one sheep showed that almost no hydrogenation of the esterified unsaturated acids had taken place. However, when rumen contents of a second sheep were used the neutral lipids remaining after $32 \%$ hydrolysis of the oil did show changes in fatty acid composition though, as Table 3 shows, the free fatty acids were more extensively modified. In this particular experiment, in contrast to previous experiments with rumen contents of a different sheep (Table 2), hydrogenation did not result in enhanced amounts of stearic acid being produced (compare Wright, 1960), though much of the linolenic acid was converted to $\mathrm{C}_{\mathbf{1 8}}$ monoand di-unsaturated acids; further, no additional palmitic acid was produced.

Table 3. Composition of the free fatty acids and the fatty acids of the neutral lipids following partial hydrolysis of linseed oil and, for comparison, that of the fatty acids of the linseed oil glycerides

Dash ( $\rightarrow$ ) indicates not detected.

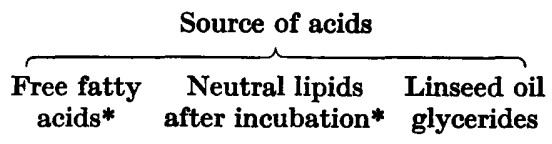

Fatty acid

Unidentified
$\mathrm{C}_{18}$ saturated (palmitic)
$\mathrm{C}_{18}$ saturated (stearic)
$\mathrm{C}_{18}$ mono-unsaturated
$\mathrm{C}_{18}$ di-unsaturated
$\mathrm{C}_{18}$ tri-unsaturated

\begin{tabular}{|c|c|c|}
\hline \multicolumn{3}{|c|}{ Composition (weight \%) } \\
\hline 0.7 & - & - \\
\hline $5 \cdot 7$ & $5 \cdot 3$ & $5 \cdot 7$ \\
\hline $4 \cdot 0$ & $\mathbf{5} \cdot 2$ & $4 \cdot 2$ \\
\hline $\mathbf{2 4} \cdot \mathbf{4}$ & $18 \cdot 8$ & $15 \cdot 6$ \\
\hline $38 \cdot 4$ & $21 \cdot 6$ & $13 \cdot 2$ \\
\hline $26 \cdot 8$ & $49 \cdot 1$ & $61 \cdot 3$ \\
\hline
\end{tabular}

* Due allowance having been made for the contribution of the lipids in the rumen contents per se.

\section{Incubation of glycerol with rumen contents}

The hydrolysis of glycerides raises the question of the fate of the glycerol which is liberated. As already noted, no glycerol was detected in rumen contents following the almost complete hydrolysis of linseed oil. Similarly, when $0.5 \mathrm{~g}$. amounts of glycerol were incubated anaerobically at $37^{\circ}$ for $24 \mathrm{hr}$. with $100 \mathrm{ml}$. rumen contents (from a sheep fed on hay and concentrates) no glycerol was detectable after this time. In further experiments, 0.5-1.0 g. glycerol was incubated with $100 \mathrm{ml}$. rumen contents and small samples $(1.0 \mathrm{ml}$.) were removed for glycerol determination at intervals up to $24 \mathrm{hr}$. after the start of the incubation. Within $2 \mathrm{hr}$. less than $80 \%$ 
of the initial amount of glycerol was present, within $4 \mathrm{hr}$. only about $50 \%$ remained and the rest gradually disappeared within $24 \mathrm{hr}$. (Table 4). In no experiment did volatile fatty acids account for more than $50 \%$ of the glycerol which was metabolized; the predominant acid produced was propionic acid.

\section{Table 4. Metabolism of glycerol in sheep rumen contents}

Glycerol $(0.580 \mathrm{~g}$.) was added to $100 \mathrm{ml}$. rumen contents.

$\begin{array}{cc}\begin{array}{c}\text { Time after } \\ \text { adding glycerol } \\ \text { (hr.) }\end{array} & \begin{array}{c}\text { Recovery of } \\ \text { added glycerol } \\ (\%)\end{array} \\ 0 & 100 \\ 2 & 77 \cdot 8 \\ 4 & 50 \cdot 0 \\ 6 & 28 \cdot 3 \\ 9 & 13 \cdot 3 \\ 23 & 1 \cdot 1 \\ 24 & 0\end{array}$

Possible intermediates in glyceride hydrolysis

In incubation experiments in which hydrolysis of linseed oil was less than $80 \%$ after $24 \mathrm{hr}$. the neutral lipids were examined for the presence of possible intermediates of lipolysis, namely, mono- and di-glycerides. The chromatographic procedures of Borgström (1954), Barron \& Hanahan (1958) and Hirsch \& Ahrens (1958) all failed to reveal the presence of partial glycerides. Similar negative findings also resulted from analyses of the neutral lipids of samples of the incubation mixture taken at several intervals during the course of a $24 \mathrm{hr}$. incubation of linseed oil with rumen contents, although 'normal' hydrolysis progressively took place as evidenced by the increasing proportion of free fatty acids in the total lipids of the samples.

Table 5. Free fatty acids in the alimentary tracts of two slaughtered sheep

For diets of sheep, see Methods.

$\begin{array}{lc}\text { Source of digesta } & \begin{array}{r}\text { Free fatty acids } \\ \text { as \% total } \\ \text { fatty acids }\end{array} \\ \text { Sheep 1 } & \\ \text { Rumen } & 92 \\ \text { Abomasum } & 90 \\ \text { Small intestine (upper) } & 96 \\ \text { Small intestine (lower) } & 94 \\ \text { Rumen Sheep 2 } & \\ \text { Abomasum } & \\ \text { Small intestine (total) } & \mathbf{7 8}\end{array}$

\section{Alimentary tract contents}

The proportion of free fatty acids in the total fatty acids obtained from the rumen, abomasum and small intestine of two sheep is given in Table 5. As described under Methods, sheep no. 1 was given the diet containing linseed oil and sheep 
no. 2 was fed largely on concentrates. The greater part of the total fatty acids of the alimentary tract contents of both animals was in the form of free higher fatty acids; gas chromatographic analysis of those derived from sheep no. 2 showed that stearic acid, palmitic acid and $\mathrm{C}_{18}$ mono-unsaturated acid were the major components of the acids in each of the three parts of the tract which were examined (compare the free fatty acids of rumen contents given in Table 2).

\section{DISCUSSION}

Though it has been known for some time that carbohydrates and proteins undergo hydrolytic and fermentative changes in the rumen, little attention has hitherto been paid to the fate of lipids which constitute as much as 5-10\% of the dry weight of many common feedingstuffs. As outlined in the Introduction, it has been established within the last decade that centres of unsaturation of fatty acids can be hydrogenated in the rumen, apparently under the influence of the micro-organisms present. The findings of the present work now show that the micro-organisms can effect considerable hydrolysis of fatty acids from glyceride combination and, since the preliminary report of these studies appeared (Garton et al. 1958), Dawson (1959) has found that phospholipids too can be hydrolysed to their components (i.e. fatty acids, glycerol and a nitrogenous base) by sheep rumen organisms. Thus ingested feed lipids can be pre-digested in the rumen and most of the higher fatty acids in the digesta leaving the rumen are, as Table 5 shows, in the free state. This is a situation markedly different from that in simple-stomached animals in which ingested lipids are not subject to hydrolysis until they reach the small intestine.

It is concluded that rumen bacteria produce a lipase and, as the following paper (Hobson \& Mann, 1961) describes, lipolytic bacteria have been isolated from sheep rumen contents. Since no enzyme activity was detected in rumen contents except in the presence of micro-organisms, the lipolysis must take place either within the bacteria or at the point of contact between bacterium and lipid particle. No monoor di-glycerides were detected during the lipolysis of triglyceride, indicating that, if formed at all, these possible intermediates have a very transient existence. Indeed, it appears that the enzyme system is non-specific in its activity towards fatty acids occupying the $\alpha$ - and $\beta$-positions on the glycerol molecule; in this respect the system seems to resemble lipoprotein lipase rather than pancreatic lipase (compare Korn, 1960).

The hydrogenation of the unsaturated fatty acids of triglycerides apparently takes place more rapidly when they are split off rather than when they are in glyceride combination. It should be mentioned that hydrogenation results in the production of spatial and positional isomers of unsaturated acids (Shorland et al. 1957); these are included, where appropriate, in Tables 2 and 3 under the heading ' $\mathrm{C}_{18}$ mono-, di- and tri-unsaturated acids'. Linolenic acid forms a very large proportion of the total fatty acids of pasture grasses (Garton, 1960). Our studies have confirmed the observations of Shorland et al. (1957) that this acid is particularly effectively hydrogenated. The micro-organisms responsible for hydrogenating double bonds and the source of the necessary hydrogen have not yet been investigated, though Wright $(1959,1960)$ has shown that, in addition to bacteria, protozoa are probably involved. 
In the experiments illustrated in Table 2 some additional palmitic acid was apparently formed in some way at the expense of the $\mathrm{C}_{18}$ fatty acids of linseed oil, olive oil and cocoa butter. Though no significantly increased amounts of lower volatile fatty acids were produced during these incubations, it seems possible that the palmitic acid was formed from stearic acid. This question forms part of a current investigation using synthetic glycerides containing ${ }^{14} \mathrm{C}$-labelled stearic acid. In connexion with the occurrence of free higher fatty acids in rumen lipids, it may be noted that there is no evidence that they can be synthesized in significant amounts de novo in the rumen other than in the formation of the lipids within the microorganisms themselves. Gray, Pilgrim, Rodda \& Weller (1952) showed that when ${ }^{14} \mathrm{C}$-labelled acetate or ${ }^{14} \mathrm{C}$-labelled propionate were incubated with sheep rumen contents, butyrate arose by condensation of acetate units, and valerate by condensation of acetate and propionate units; no significant synthesis of longer-chain acids was observed.

Johns (1953) showed that the fermentation of free glycerol by sheep rumen contents in vitro and in vivo led to the formation of propionic acid. That propionic acid is the principal volatile fatty acid produced was confirmed in the present work, though no more than $50 \%$ of the glycerol which was metabolized could be accounted for on a 'carbon balance' basis; the fate of the remainder has still to be investigated. As described in the following paper (Hobson \& Mann, 1961), relatively more of the glycerol carbon was accounted for as volatile fatty acids (largely propionic) when glycerol-fermenting organisms from sheep rumen were grown in media containing glycerol or glycerol + acetate.

Triglycerides, though present in the lipids of concentrates made from seeds (e.g. linseed meal, maize meal, groundnut meal), do not form a very high proportion of the lipids of such feeds as grasses and clover in which galactosyl glyceryl esters of fatty acids predominate (Weenink, 1959; Garton, 1960). Though the metabolism of these esters by rumen micro-organisms has not yet been studied in detail, preliminary experiments indicate that they are readily hydrolysed.

We wish to thank Dr M. I. Chalmers and Dr T. R. Preston for making the slaughtered sheep available to us and to acknowledge the skilled technical assistance of Mr N. I. Lovie and Mr W. Smith in the course of this work. One of us (E. V.) was Juan March Foundation Fellow on study leave from the Instituto de la Grasa y sus Derivados, Sevilla, Spain, when his contribution to this work was carried out.

\section{REFERENCES}

Barron, E. J. \& Hanahan, D. J. (1958). Observations on the silicic acid chromatography of the neutral lipids of rat liver, beef liver and yeast. J. biol. Chem. 231, 493.

Borgström, B. (1954). Lipid separation methods. III. Separation of tri-, di-, 1-monoand 2-monoglycerides. Acta physiol. scand. 30, 231.

Dawson, R. M. C. (1959). Hydrolysis of lecithin and lysolecithin by rumen microorganisms of the sheep. Nature, Lond. 183, 1822.

ElsDEN, S. R. \& LEwIS, D. (1953). The production of fatty acids by a Gram-negative coccus. Biochem. J. 55, 183.

Farquhar, J. W., Insuld, W., Rosen, P., Stoffel, W. \& Ahrens, E. H. (1959). The analysis of fatty acid mixtures by gas-liquid chromatography. Supplement (Number 8 , Part II) to Nutr. Rev. 17. 
Friedemann, T. E. (1938). The identification and quantitative determination of volatile alcohols and acids. J. biol. Chem. 123, 161.

Garton, G. A. (1959). Lipids in relation to rumen function. Proc. Nutr. Soc. 18, 112.

Garton, G. A. (1960). Fatty acid composition of the lipids of pasture grasses. Nature, Lond. 187, 511.

Garton, G. A., Hobson, P. N. \& Lough, A. K. (1958). Lipolysis in the rumen. Nature, Lond. 182, 1511.

Garton, G. A., Lough, A. K. \& Vioque, E. (1959). The effect of sheep rumen contents on triglycerides in vitro. Biochem. J. 73, $46 \mathrm{P}$.

Gray, F. V., Pilgrim, A. F., Rodda, H. J. \& Weller, R. A. (1952). Fermentation in the sheep. IV. The nature and origin of the volatile fatty acids in the rumen of the sheep. J. exp. Biol. 29, 57.

Hirsch, J. \& Ahrens, E. H., Jun. (1958). The separation of complex lipid mixtures by the use of silicic acid chromatography. J. biol. Chem. 233, 311.

Hobson, P. N. \& ManN, S. O. (1961). The isolation and culture of glycerol-fermenting and lipolytic bacteria from the rumen of the sheep. J. gen. Microbiol. 25, 227.

JoHNs, A. T. (1953). Fermentation of glycerol in the rumen of the sheep. N.Z. J. Sci. Tech. $35 \mathrm{~A}, 262$.

Konn, E. D. (1960). The fatty acid and positional specificities of lipoprotein lipase. Abstr. Comms. 5th int. Conf. Biochem. Problems of Lipids, p. 20.

Lambert, M. \& Neish, A. C. (1950). Estimation of glycerol. Canad. J. Res. 28, 83.

REISER, R. (1951). Hydrogenation of polyunsaturated fatty acids by the ruminant. Fed. Proc. 10, 236.

Reiser, R. \& REDDy, H. G. R. (1956). The hydrogenation of dietary unsaturated fatty acids by the ruminant. J. Amer. Oil Chem. Soc. 33, 155.

Shorland, F. B., Weenink, R. O. \& Johns, A. T. (1955). Effect of the rumen on dietary fat. Nature, Lond. 175, 1129.

Shorland, F. B., WeEnink, R. O., Johns, A. T. \& McDonald, I. R. C. (1957). The effect of sheep-rumen contents on unsaturated fatty acids. Biochem. J. 67, 328.

WeEnINK, R. O. (1959). A note on the acetone-soluble lipids of forage grasses and clovers. N.Z. J. Sci. 2, 273.

Wrighr, D. E. (1959). Hydrogenation of lipids by rumen protozoa. Nature, Lond. 184, 875.

Wright, D. E. (1960). Hydrogenation of chloroplast lipids by rumen bacteria. Nature, Lond. 185, 546. 